\title{
Effect of ethylene on postharvest strawberry fruit tissue biochemistry
}

\author{
F. Elmi*, I. Pradas*, R. Tosetti, K. Cools and L.A. Terry \\ Plant Science Laboratory, Cranfield University, Bedfordshire, UK. \\ * These authors contributed equally to this work
}

\begin{abstract}
The effect of continuous ethylene supplementation (50 $\mu \mathrm{L} \mathrm{L}^{-1}$ ) on cold-stored strawberry fruit physiology and biochemistry, including phytohormones (abscisic acid) metabolism was investigated. In comparison with control fruit which exhibited high sucrose and malic acid contents during storage, ethylene-treated fruits showed increased respiration, sucrose hydrolysis and concomitant reducing sugars accumulation. Ethylene supplementation did not have any effect on phenolic profile. ABA biosynthesis, in both flesh and achenes, was promoted by ethylene. The results herein suggest that controlling ethylene after harvest could suppress senescence and extend shelf-life.
\end{abstract}

Keywords: Abscisic acid, continuous ethylene supplementation, senescence, shelf-life, sugars hydrolysis.

\section{INTRODUCTION}

Strawberry (Fragaria x ananassa) fruit, is classified as non-climacteric yet has exhibited climacteric-like activity. In particular, receptacle tissue showed a partially similar climacteric ripening, while achene ripening was not comparable to climacteric fruits, likely due to dry pericarp feature (Trainotti et al., 2005; Iannetta et al., 2006; Merchante et al., 2013). It has been demonstrated that approximately half of ethylene produced in planta was attributable to the achenes during the green and red stages, while in the receptacle ethylene production was more active during the green-white shift (Iannetta et al., 2006; Merchante et al., 2013).

Besides ethylene, auxins and abscisic acid (ABA) play an important role in strawberry fruit development and postharvest: auxins have been associated with the inhibition of receptacle ripening, while $\mathrm{ABA}$ has been shown to promote pre-harvest ripening and auxin decline (Given et al., 1988; Manning, 1994; Jia et al., 2011; Symons et al., 2012). Moreover, postharvest ABA applications accelerated fruit colour development and fruit softening, 
stimulating ethylene production (Jiang and Joyce, 2003; Li et al., 2013); it has also been proposed that $\mathrm{ABA}$, together with the ethylene, was up-regulated when fruits were exposed to abiotic and or biotic stress (Terry et al., 2007a; Li et al., 2013). Given the influence of phytohormones flux in strawberry ripening, it is surprising that little work has evaluated the role of ethylene and other phytohormones postharvest.

The aim of this study was to determine the effect of postharvest ethylene supplementation on strawberry fruits physiology and biochemistry, with particular interest in cross talk with other phytohormones in both achenes and receptacle tissue.

\section{MATERIAL AND METHODS}

Strawberries, cv. Sonata, were purchased from a local grower (H \& H Duncalfe in Cambridgeshire, UK) and transferred to the Plant Science Laboratory within $2 \mathrm{~h}$ from harvest (6 $6^{\text {th }}$ August 2012). On arrival, fruits of similar size and weight were selected and stored at $5^{\circ}$ $\mathrm{C}$ within polypropylene boxes, sealed with a moat of water providing an air tight. Sealed boxes were constantly flushed, with air (control) or air mixed with ethylene (50 $\left.\mathrm{L} \mathrm{L}^{-1}\right)$, to ensure complete air exchange and prevent accumulation of carbon dioxide $\left(\mathrm{CO}_{2}\right)$. The concentration of ethylene was quantified using a flame ionisation gas chromatography as described previously (Chope et al., 2007; Terry et al., 2007b). Fruits were stored for six days at $5^{\circ} \mathrm{C}$ and analysed at five time points: day 0 (before treatments) and days 1, 2, 4, 6 (after treatments). Strawberries, as whole fruit, were tested for $\mathrm{CO}_{2}$ and ethylene production, sugars, organic acids and phenolic compounds, while phytohormones contents were analysed in different tissues samples (flesh and achenes). $\mathrm{CO}_{2}$ production was checked using a Sable Respirometry System (Model 1.3.8 Pro, Sable Systems International, NV, USA), as previously described by Collings et al. (2012), while ethylene production was monitored continuously (for $3 \mathrm{~h}$ ) with a laser based photoacoustic ethylene detector (ETD-300; Sensor Sense B.V., Nijmegen, The Netherlands); ethylene evolution was measured at ambient temperature $\left(18^{\circ} \mathrm{C} \pm 1^{\circ} \mathrm{C}\right)$. Biochemical and metabolomics extracts were obtained from freeze-dried material. Sugars, organic acids and phenolic compounds were quantified using an Agilent 1200 series HPLC binary pump system (Agilent, Berks., UK) coupled with an Agilent refractive index detector (RID) G1312A and with an Agilent 1200 DE G1364C/G1315D photodiode array detector, respectively. Phytohormones were extracted from different tissues and quantified as previously described by Ordaz-Ortiz et al. (2015) using an Agilent 6540 Ultra High Definition Accurate Mass Q-TOF LC-MS System. ANOVA of results was performed using STATISTICA software for Windows $12^{\text {th }}$ Edition (StatSoft Inc.). 


\section{RESULTS AND DISCUSSION}

While ethylene production was not affected by treatment, respiration rate $\mathrm{CO}_{2}$ production) showed an increase following ethylene supplementation. In particular, a slight increase in $\mathrm{CO}_{2}$ production of control fruits during the first $24 \mathrm{~h}$ of storage was detected, likely due to the variation of surrounding environment (100.48 $\left.\mathrm{ml} \mathrm{CO}_{2} \mathrm{~kg}^{-1} \mathrm{~h}^{-1}\right)$. Once control strawberries had been conditioned, respiration rate halved and was significantly different in comparison with ethylene treated strawberry. Ethylene treated fruits exhibited 2 fold higher $\mathrm{CO}_{2}$ production values $\left(115.96 \mathrm{ml} \mathrm{CO}_{2} \mathrm{~kg}^{-1} \mathrm{~h}^{-1}\right.$ at day two and $99.80 \mathrm{ml} \mathrm{CO}_{2} \mathrm{~kg}^{-1} \mathrm{~h}^{-1}$ at day four. Fig. 1).

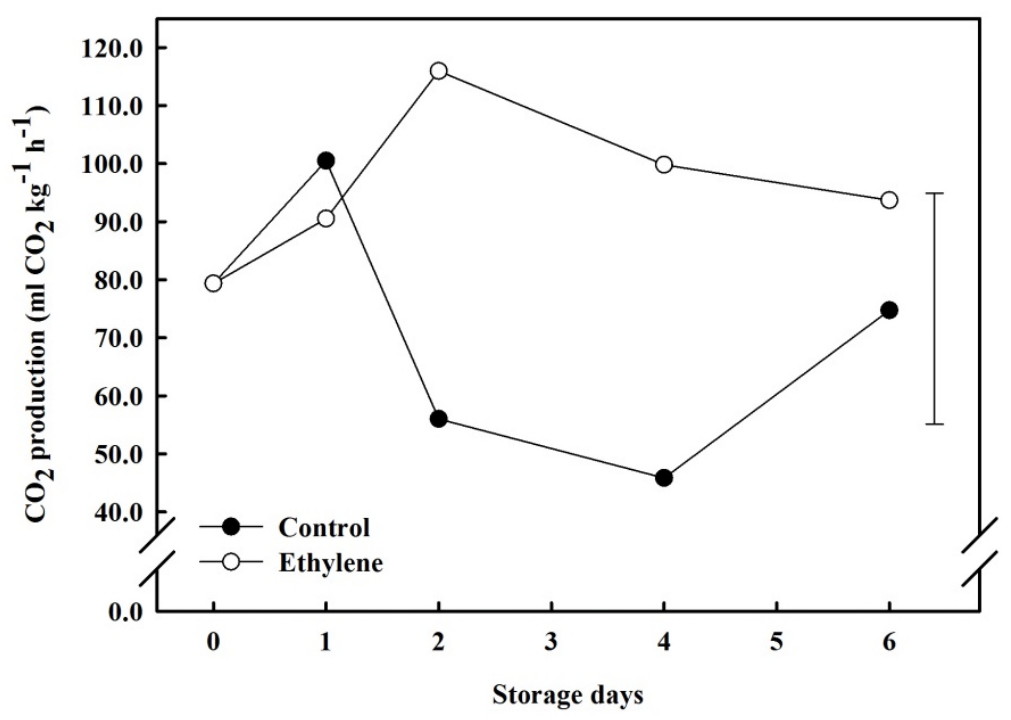

Figure 1: $\mathrm{CO}_{2}$ production of ethylene treated (white dot) and air stored strawberry fruits (black dot). Vertical bar indicates LSD $(P<0.05)$.

Continuous ethylene supplementation did not effect on phenolic content. In contrast, ethylene treatment promoted the accumulation of reducing sugars concomitant with sucrose hydrolysis (Figs. 2A, 2B and 2C); at the same time, a decline in malic acid was detected in ethylene treated strawberry fruit compared to control fruits (Fig. 2D). 

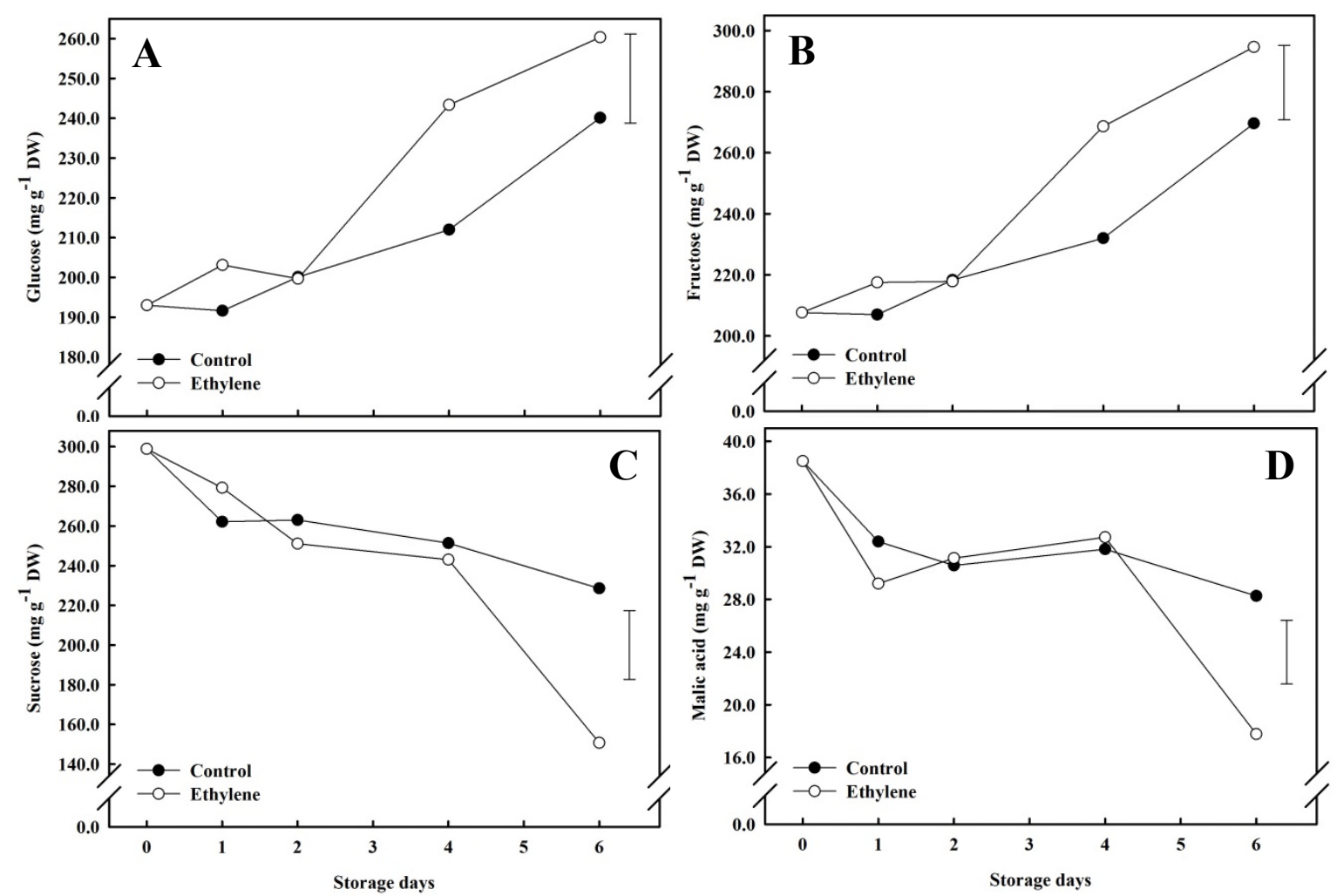

Figure 2: Effect of continuous ethylene supplementation (50 $\mu \mathrm{l} \mathrm{L}-1)$ on sugars and malic acid in treated strawberry (white dot) and in air stored fruits (black dot). A, Glucose accumulation; B, Fructose accumulation; C, Sucrose hydrolysis; D, Malic acid metabolism. Vertical bars indicate LSD $(P<0.05)$.

ABA biosynthesis was induced in all fruit tissues by continuous ethylene supplementation. In particular, a significant and constant increase of ABA was measured in the flesh of ethylene treated strawberries (Fig. 3A), while in achenes the difference between control and treated fruits was detected only at the end of cold storage (Fig. 3B). 
A

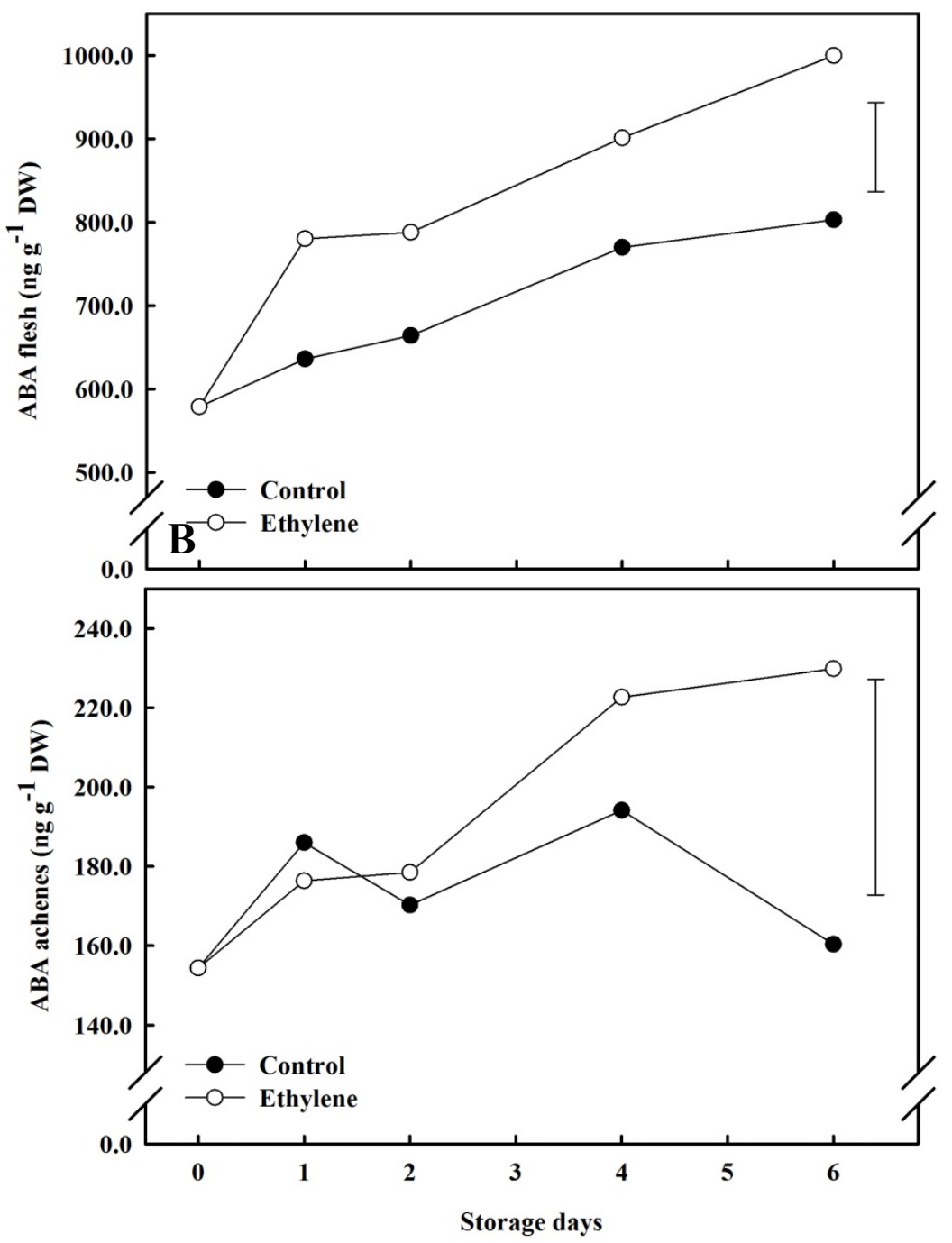

Figure 3: Effect of continuous ethylene supplementation $(50 \mu \mathrm{l} \mathrm{L}-1)$ on ABA biosynthesis in flesh and achenes of treated strawberry (white dot) and of air stored fruits (black dot). A, ABA biosynthesis in flesh tissue; B, ABA biosynthesis in achenes tissue. Vertical bars indicate LSD $(P<0.05)$.

It is well documented that non-climacteric fruits produce minimal ethylene and exhibit low respiration during both ripening and postharvest stages; nevertheless, ethylene can impact on postharvest stage of strawberry. The results of this work highlighted that ethylene supplementation enhanced respiration rate, sucrose hydrolysis and organic acids decrease. These data are in agreement with previous studies where ethylene treatment has been found to promote strawberry colour development and reducing sugars accumulation, while inhibition of ethylene perception led to decreased organic acids metabolism (Perkins-Veazie et al., 1996; Villarreal et al., 2010; Merchante et al., 2013). Changes in sugars-organic acids ratio in strawberry represent an important indicator of fruit taste and quality (Giné 
Bordonaba and Terry, 2009); variations in sugars and organic acids amounts, as well as increase in respiration activity, are often correlated with ripening and senescence processes onset. In particular, the decrease in sucrose over time has been identified as an indicator of fruit senescence (Cordenunsi et al., 2003; Olsson et al., 2004; Kafkas et al., 2007).

Similarly, ABA production and accumulation have been widely related to senescence in both climacteric and non-climacteric fruits (Terry et al., 2007a; Chen et al., 2011; Li et al., 2013). Evidence of the central role of $A B A$ in regulating strawberry ripening has been identified by Jia et al. (2011), which demonstrated that ABA biosynthesis and perception was crucial for anthocyanins production. Recently, Medina-Puche et al. (2013) found that FaMYB10 expression was down-regulated by auxins and up-regulated by ABA; the transcription factor FaMYB10 has been related to the expression of flavonoid/phenylpropanoid $E B G$ s and $L B G$ s (Early- and Late-regulated Biosynthesis group of Genes, respectively). Moreover, it has been noted that ABA induced the ethylene biosynthesis pathway during strawberry ripening and following abiotic and biotic stress imposition, both during stress conditions (Jang et al., 2003; Terry et al., 2007a); in this study, metabolomics data showed that ethylene supplementation promoted ABA biosynthesis. Significant differences between $\mathrm{ABA}$ concentration in both flesh and achenes were observed following ethylene supplementation; the increased ABA biosynthesis in flesh of ethylene treated strawberries confirmed the ripening-like features of receptacle tissues (Trainotti et al., 2005; Merchante et al., 2013).

In conclusion, postharvest continuous ethylene supplementation accelerated senescence in strawberry fruits, having an effect mostly on respiration activity, biochemical compounds metabolism and abscisic acid biosynthesis.

\section{ACKNOWLEDGEMENTS}

Dr. Pradas would like to thank the Institute of Agricultural and Fisheries Research and Training (IFAPA) and the European Social Fund (2007-2013) for the postdoctoral fellowship. Dr Elmi would like to extend gratitude to Johnson Matthey Plc and Engineering and Physical Sciences Research Council (EPSRC) for the financial support. 


\section{Literature cited}

Chen, J., Liu, D., Jiang, Y., Zhao, M., Shan, W., Kuang, J. and Lu, W. (2011). Molecular characterization of a strawberry FaASR gene in relation to fruit ripening. PloS One 6, e24649.

Chope, G.A., Terry, L.A. and White, P.J. (2007). The effect of 1-methylcyclopropene (1-MCP) on the physical and biochemical characteristics of onion cv. SS1 bulbs during storage. Postharvest Biol. and Tech. 44, 131-140.

Collings, E., Garcia Cas, J.A., Ordaz-Ortiz, J.J. and Terry, L.A. (2012). A new real-time automated method for measuring in situ respiration rates of fresh produce. $7^{\text {th }}$ IPS2012, 25-29th May, Kuala Lumpur, Malaysia.

Cordenunsi, B.R., Nascimento, J.R.O. and Lajolo, F.M. (2003). Physico-chemical changes related to quality of five strawberry fruit cultivars during cool-storage. Food Chem. 83, 167-173.

Giné Bordonaba, J. and Terry, L.A. (2009). Development of a glucose biosensor for rapid assessment of strawberry quality: relationship between biosensor response and fruit composition. J. Agr. Food Chem. 57, 8220-8226.

Given, N., Venis, M. and Gierson, D. (1988). Hormonal regulation of ripening in the strawberry, a non-climacteric fruit. Planta 174, 402-406.

Iannetta, P.P.M., Laarhoven, L.J., Medina-Escobar, N., James, E.K., McManus, M.T., Davies, H.V. and Harren, F.J.M. (2006). Ethylene and carbon dioxide production by developing strawberries show a correlative pattern that is indicative of ripening climacteric fruit. Physiol. Plantarum 127, 247-259.

Kafkas, E., Koşar, M., Paydaş, S., Kafkas, S. and Başer, K. (2007). Quality characteristics of strawberry genotypes at different maturation stages. Food Chem. 100, 1229-1236.

Jia, H., Chai, Y., Li, C., Lu, D., Luo, J., Qin, L. and Shen, Y. (2011). Abscisic acid plays an important role in the regulation of strawberry fruit ripening. Plant Physiol. 157, 188-199.

Jiang, Y. and Joyce, D.C. (2003). ABA effects on ethylene production, PAL activity, anthocyanin and phenolic contents of strawberry fruit. Plant Growth Regul. 39, 171-174.

Li, D., Luo, Z., Mou, W., Wang, Y., Ying, T. and Mao, L. (2013). ABA and UV-C effects on quality, antioxidant capacity and anthocyanin contents of strawberry fruit (Fragaria ananassa Duch.). Postharvest Biol. and Tech. 90, 56-62.

Manning, K. 1994. Changes in gene expression during strawberry fruit ripening and their regulation by auxin. Planta 194, 62-68.

Medina-Puche, L., Cumplido-Laso, G., Amil-Ruiz, F., Hoffmann, T., Ring, L., Rodríguez-Franco, A., Caballero, J.L., Schwab, W., Muñoz-Blanco, J. and Blanco-Portales, R. (2013). MYB10 plays a major role in the regulation of flavonoid/phenylpropanoid metabolism during ripening of Fragaria $\times$ ananassa fruits. J. Exp. Bot. 65, 410-417

Merchante, C., Vallarino, J.G., Osorio, S., Aragüez, I., Villarreal, N., Ariza, M.T., Martínez, G.A., Medina-Escobar, N., Civello, M.P., Fernie, A.R. et al. (2013). Ethylene is involved in strawberry fruit ripening in an organ-specific manner. J. Exp. Bot. 64, 4421-4439.

Olsson, M.E., Ekvall, J., Gustavsson, K., Nilsson, J., Pillai, D., Sjöholm, I., Svensson, U., Åkesson, B. and Nyman, M.G.L. (2004). Antioxidants, low molecular weight carbohydrates, and total antioxidant capacity in strawberries (Fragaria $\times$ ananassa): effects of cultivar, ripening, and storage. J. Agr. Food Chem. 52, 2490-2498.

Ordaz-Ortiz, J.J., Foukaraki, S.G. and Terry, L.A. (2015). Assessing temporal flux of plant hormones in stored processing potatoes using high definition accurate mass spectrometry. Hortic Res. 2,15002..

Perkins-Veazie, P.M., Huber, D.J. and Brecht, J.K. (1996). In vitro growth and ripening of strawberry fruit in the presence of ACC, STS or propylene. Ann. Appl. Biol. 128, 105-116.

Symons, G., Chua, Y., Ross, J., Quittenden, L., Davies, N. and Reid, J. (2012). Hormonal changes during non-climacteric ripening in strawberry. J. Exp. Bot. 63, 4741-4750.

Terry, L.A., Chope, G.A. and Giné Bordonaba, J. (2007a). Effect of water deficit irrigation and inoculation with Botrytis cinerea on strawberry (Fragaria x ananassa) fruit quality. J. Agr. Food Chem. $55,10812-10819$.

Terry, L.A., Ilkenhans, T., Poulston, S., Rowsell, L. and Smith, A.W.J. (2007b). Development of new palladium-promoted ethylene scavenger. Postharvest Biol. and Tech. 45, 214-220. 
Trainotti, L., Pavanello, A. and Casadoro, G. (2005). Different ethylene receptors show an increased expression during the ripening of strawberries: does such an increment imply a role for ethylene in the ripening of these non-climacteric fruits? J. Exp. Bot. 56, 2037-2046.

Villarreal, N.M., Bustamante, C.A., Civello, P.M. and Martínez, G.A. (2010). Effect of ethylene and 1-MCP treatments on strawberry fruit ripening. J. Sci. Food Agr. 90, 683-689. 